\title{
Taxonomic and chemical assessment of exceptionally abundant rock mine biofilm
}

\author{
Karolina Tomczyk-Żak ${ }^{1}$ ， Paweł Szczesny ${ }^{2,3}$, Robert Gromadka ${ }^{4}$, Urszula Zielenkiewicz ${ }^{\text {Corresp. } 5}$ \\ 1 Department of Microbial Biochemistry, Institute of Biochemistry and Biophysics, PAS, Warsaw, Poland \\ 2 Faculty of Biology, Institute of Experimental Plant Biology and Biotechnology, University of Warsaw, Warsaw, Poland \\ 3 Department of Bioinformatics, Institute of Biochemistry and Biophysics Polish Academy of Sciences, Warsaw, Poland \\ 4 Laboratory of DNA Sequencing and Oligonucleotides Synthesis, Institute of Biochemistry and Biophysics, PAS, Warsaw, Poland \\ 5 Department of Microbial Biochemistry, Institute of Biochemistry and Biophysics PAS, Warsaw, Poland \\ Corresponding Author: Urszula Zielenkiewicz \\ Email address: ulazet@ibb.waw.pl
}

Background: An exceptionally thick biofilm covers walls of ancient gold and arsenic Złoty Stok mine (Poland) in the apparent absence of organic sources of energy. Methods and Results: We have characterized this microbial community using culture-dependent and independent methods. We sequenced amplicons of the 16S rRNA gene obtained using generic primers and additional primers targeted at Archaea and Actinobacteria separately. Also, we have cultured numerous isolates from the biofilm on different media under aerobic and anaerobic conditions. We discovered very high biodiversity, and no single taxonomic group was dominant. The majority of almost 4000 OTUs were classified above genus level indicating presence of novel species. Elemental analysis, performed using SEM-EDS and X-ray, of biofilm samples showed that carbon, sulphur and oxygen were not evenly distributed in the biofilm and that their presence is highly correlated. However, the distribution of arsenic and iron was more flat, and numerous intrusions of elemental silver and platinum were noted, indicating that microorganisms play a key role in releasing these elements from the rock. Conclusions: Altogether, the picture obtained throughout this study shows a very rich, complex and interdependent system of rock biofilm. The chemical heterogeneity of biofilm is a likely explanation as to why this oligotrophic environment is capable of supporting such high microbial diversity. 
1 Taxonomic and chemical assessment of exceptionally abundant rock mine

\section{2 biofilm}

4 Karolina Tomczyk-Żak ${ }^{1}$, Paweł Szczesny ${ }^{1,2}$, Robert Gromadka ${ }^{1}$, Urszula Zielenkiewicz ${ }^{1 *}$

5 1Institute of Biochemistry and Biophysics, Polish Academy of Sciences, Warsaw, Poland

62 University of Warsaw, Faculty of Biology, Institute of Experimental Plant Biology and

7 Biotechnology, Warszawa, Poland.

8

9 *Corresponding author: UrszulaZielenkiewicz;

10 Email address: ulazet@,ibb.waw.pl

Running title: Microbial diversity of a rock mine biofilm. 
Abstract

21 Background: An exceptionally thick biofilm covers walls of ancient gold and arsenic Złoty Stok 22 mine (Poland) in the apparent absence of organic sources of energy. Methods and Results: We

23 have characterized this microbial community using culture-dependent and independent methods.

24 We sequenced amplicons of the 16S rRNA gene obtained using generic primers and additional 25 primers targeted at Archaea and Actinobacteria separately. Also, we have cultured numerous 26 isolates from the biofilm on different media under aerobic and anaerobic conditions. We 27 discovered very high biodiversity, and no single taxonomic group was dominant. The majority of 28 almost 4000 OTUs were classified above genus level indicating presence of novel species. 29 Elemental analysis, performed using SEM-EDS and X-ray, of biofilm samples showed that carbon, sulphur and oxygen were not evenly distributed in the biofilm and that their presence is highly correlated. However, the distribution of arsenic and iron was more flat, and numerous intrusions of elemental silver and platinum were noted, indicating that microorganisms play a key role in releasing these elements from the rock. Conclusions: Altogether, the picture obtained throughout this study shows a very rich, complex and interdependent system of rock biofilm. The chemical heterogeneity of biofilm is a likely explanation as to why this oligotrophic environment is capable of supporting such high microbial diversity. 


\section{Introduction}

41

42 The mutual interactions of microbes with surroundings result in both environmental and 43 microbial community changes. The significant role of active microorganisms in element 44 biotransformations and biogeochemical cycling, metal and mineral transformations has been recognized (Gadd, 2010). The structure of microbial communities in a particular environment 46 depends on specific physical and chemical conditions: humidity, $\mathrm{pH}$, temperature, salinity, 47 concentration of oxygen, heavy metals and other toxic compounds, and the availability of 48 electron acceptors and carbon sources.

Sub-aerial biofilms, ubiquitous on the solid surfaces exposed to the atmosphere, form relatively stable miniature ecosystems that contribute to the weathering of natural rocks and human constructions (Gorbushina, 2007).Similarly, the diversity and abundance of epi- and endolithic prokaryotic communities in the deep sea also positively correlates with the extent of rock alteration(Santelli et al., 2009). However, only sporadic development of microorganisms on the

54 surfaces in the form of abundant biofilms has been documented. In most cases these were the micro-colonies on prehistorical paintings in caves (Schabereiter-Gurtner et al., 2002a; Portillo et al., 2008, 2009; Schabereiter-Gurtner et al., 2002b, 2004) or populations colonizing historical monuments (Gorbushina et al., 2002; Zimmermann et al., 2006).In turn, in caves with acidic pH, a population of biofilms called "snottites"is limited only to a few microbial species (Macalady et 59 al., 2007).

60 Contrary to caves, mines are not considered a "natural" environment. An interest in the biodiversity of mines is associated with the strong negative effects of mining activities on the 62 environment, particularly on ground and surface waters. Most well-studied mine ecosystems 
63 inhabit both rock surfaces as well as a mining waste such as slag heaps and acidic, metal-rich

64 waters referred to as "acid mine drainage" (AMD) or "acid rock drainage" (ARD). AMD

65 environments are the result of the accelerated oxidation of exposed minerals after exploitation of

66 metal ores and coal. Usually such environments are rich in sulphur compounds and are generally

67 characterized by high concentrations of metal ions (e.g. aluminium, copper, zinc, manganese,

68 arsenic, and especially iron) and high temperatures, which are the result of strongly exothermic

69 oxidation reactions of these compounds. The amount of organic matter is generally low $(<20$

$70 \mathrm{mg} / \mathrm{l}$ ). In the majority of acidic environments the diversity of the microbial population is low,

71 comprising one or a few dominant species (Johnson \& Hallberg, 2003; Baker \& Banfield,

72 2003), which are usually chemolithoautotrophic microorganisms that carry out oxidation and

73 reduction reactions of ferrous and sulphur ions, acidophilic heterotrophs and/or facultative

74 heterotrophs. The heterotrophs are indirectly involved in the dissolution of minerals by using

75 organic compounds (e.g. organic acids) produced by autotrophic organisms and detoxify the

76 autotrophic bacteria environment. They represent both the Bacteria and Archaea domains.

77 Few studies have examined cave or mine environments with the neutral or alkaline pH (Pasić et

78 al., 2010; Labrenz \& Banfield, 2004; Lin et al., 2006), as opposed to the acidic environment of

79 mines resulting from chemical procedures applied during the mining process. Species

80 composition in neutral or alkaline environments differs from the acidic ones and is generally

81 more diverse. Moderately alkaline $\mathrm{pH}(7.4 .-8.1)$ is a trait of the Złoty Stok gold and arsenic mine

82 geochemistry. The Złoty Stok mine in Poland has been exploited for gold since the 12th and for

83 arsenic since the 18th century. Mining ceased approximately 60 years ago, but its arsenic

84 deposits are still among the largest in the country and are the primary source of arsenic

85 contamination of surface and ground water in the area. 
86 The microbiology of this particular environment has been investigated in the context of arsenic

87 cycling. It was shown that both types of microbial communities inhabiting the mine, mats and

88 rock biofilm, can contribute to the dissemination of arsenic into mine water. Metagenomic

89 studies revealed high arr $A$ and aioA genetic diversity in these communities (Drewniak et al.,

90 2012; Tomczyk et al., 2013). Bacteria isolated from this mine can directly and indirectly

91 contribute to the mobilization of arsenic from minerals into the water and sediments (Drewniak

92 et al., 2010; Drewniak et al., 2014). However, the details of the transformation of immobilized

93 arsenic into its soluble form are still to be elucidated.

94

In previous studies the biodiversity of rock biofilm at this particular spot was analysed by 16S rRNA gene clonal analysis (Tomczyk-Żak et al., 2013). Here we present the results of the biodiversity assessment of the Złoty Stok mine biofilm obtained in culture-dependent and independent manners (using pyrosequencing method) and discuss the possible interactions of biofilm microorganisms with the environment. The biofilm, despite being present in nutritionally poor niches, has unexpectedly high diversity and complexity. This is likely explained by spatial heterogeneity shown by SEM-EDS and X-ray analyses.

\section{Materials and methods}

\section{Site description and sample collection}

The former arsenic and gold mine Złoty Stok $\left(50^{\circ} 26^{\prime} \mathrm{N}, 16^{\circ} 52^{\prime} \mathrm{E}\right)$ is located in the Sudety Mountains in southwest Poland. The mine lies within metamorphic rocks of the geological tectonic zone of the western Sudetes composed of mica and mica-quartz schists, amphibolites, leptynites, gneisses, serpentinites and crystalline limestone with characteristic polymetallic mineralisations (Przylibski, 2001). 
109 On the rock surface in the deepest section of the Gertruda Adit, a natural microbial biofilm is

110 formed (Fig. 1). In this part of the mine, the air is characterized by a stable temperature of 10.4-

$11111.1^{\circ} \mathrm{C}$, a reduced concentration of oxygen $(17.2 \%)$, and levels of arsenic hydride in the range of

112 1.52-3.23 mg/m³ (Drewniak et al., 2008). Apart from $\mathrm{CO}_{2}$ and $\mathrm{N}_{2}$, other gaseous components in

113 the Adit, including simple organic compounds (aliphatic and aromatic hydrocarbons, volatile

114 alcohols, aldehydes and acids), occur in trace amounts. The rock in the Gertruda Adit contains a

115 variety of arsenic-bearing minerals, including loellingite $\left(\mathrm{FeAs}_{2}\right)$ and arsenopyrite $(\mathrm{FeAsS})$ and

116 other minerals containing primarily iron, lead, zinc and copper, generally in the form of different 117 sulphides.

118 In November 2007, samples of biofilm were carefully collected from the walls in the end section 119 of the Gertruda Adit, $2 \mathrm{~km}$ from the entrance. Portions of biofilm of approximately $40 \mathrm{~g}$ were 120 aseptically cut from the rock directly into sterile $50-\mathrm{ml}$ tubes. These samples were stored at $4^{\circ} \mathrm{C}$ 121 and processed within $24 \mathrm{~h}$ of collection. For cultivable bacteria isolation, additional biofilm 122 sampling was performed in June 2008.

\section{DNA extraction}

124 Total biofilm DNA extraction was performed as described by Tomczyk-Żak (Tomczyk-Żak et 125 al., 2013). Briefly: biofilm samples were homogenized using glass beads in the presence of the 126 extraction buffer by shaking in a MiniBead-Beater (Bio-Spec Products), subsequently incubated 127 at $37{ }^{\circ} \mathrm{C}$ for $30 \mathrm{~min}$ with a mixture of lysozyme $(10 \mathrm{mg} / \mathrm{ml})$ and zymolyase $(0.05 \mathrm{mg} / \mathrm{ml})$, lysed 128 by addition of $20 \%$ SDS and frost-thaw repetitive cycles, after which DNA was extracted with 129 chloroform/isoamyl alcohol (24:1) and isopropanol precipitation. The DNA was further purified 
130 using the NucleoSpinTissue kit (Macherey-Nagel).Three independent biofilm samples (2 g each)

131 were processed and finally pooled for all PCR amplifications.

132 Bacterial genomic DNA was obtained after enzyme treatment (the mixture of lysozyme,

133 lysostaphin and mutanolysin) followed by the use of a commercial isolation kit (Genomic Mini

134 A\&A Biotechnology).

\section{Amplicons preparation and 454-pyrosequencing}

136

137

138

139

140

141

142

143

144

145

146

147 148

149

150

151

Separate procedures were carried out to determine the bacterial, actinobacterial and archaeal community composition. Fragments of the correspondent 16S rRNA genes were amplified from biofilm total DNA using Phusion polymerase (Finnzymes) and appropriate primers that were fused to Roche-suitable MID oligonucleotides: for Bacteria16S rDNA - universal MB-16SrF, M6-16SrR; for Actinobacteria M10- 337F, MB-1159R; for Archaea - M8-A21F, MB-1204R; and in nested PCR - M8-A21F, MB-518R (Table S1, Supplemental Information). Amplifications were performed using optimized thermal cycles (Table S2, Supplemental Information). PCR products were purified with a NucleoExtract II kit (Macherey-Nagel). The concentration and quality of the PCR products were assessed with Picogreen staining and a ChipDNA Bioanalyzer, and equal amounts were sequenced using a Roche GS FLX Titanium sequencer with a standard 454 protocol.

Sequence data from the GS FLX Titanium run has been deposited at the NCBI Short Read Archive (SRA) under project id of SRP093827.

\section{Isolation and identification of bacteria}

Bacteria were isolated from the biofilm samples (several dozen, $6 \mathrm{~g}$ in total), which were suspended in $0.8 \% \mathrm{NaCl}$ and homogenized with glass beads (Merck $1 \mathrm{~kb}$ ) by shaking for $60 \mathrm{~min}$ 
152 at room temperature. After centrifugation (10 min at $8000 \mathrm{rpm})$ the pellets were re-suspended in

153 a small volume of $0.8 \% \mathrm{NaCl}$ and spread in parallel over several types of solid media: LB (Luria

154 Bertani, Difco), selective AIA (Actinomycete Isolation Lab-Agar, Biocorp), SC (starch casein;

$155 \mathrm{~g} / \mathrm{L}$ : starch 10, casein 0.3, $\mathrm{KNO}_{3} 2, \mathrm{NaCl} 2, \mathrm{~K}_{2} \mathrm{HPO}_{4} 2, \mathrm{MgSO}_{4} \mathrm{X} 7 \mathrm{H}_{2} \mathrm{O} 0.05, \mathrm{CaCO}_{3} 0.02, \mathrm{FeSO}_{4}$

$156 \mathrm{x} \mathrm{H}_{2} \mathrm{O}$ 0.01, $\mathrm{pH}$ 7-7.2), and GYA (glycerol agar; g/L: glycerol 5, yeast extract 2, $\mathrm{K}_{2} \mathrm{HPO}_{4} 0.1$,

157 peptone 25), each containing 5\% glycerol and supplemented with $50 \mu \mathrm{g} / \mathrm{ml}$ of cycloheximide.

158 The plates were incubated at $14^{\circ} \mathrm{C}$ or $20^{\circ} \mathrm{C}$, in darkness, for up to two weeks. Part of the plates

159 were prepared and incubated under anaerobic conditions (Whitley A35 workstation).

160 Morphologically different isolates were transferred onto respective selective- and LB-agar plates

161 to obtain pure cultures.

162 The individual strains were selected using the multi-temperature single-strand conformation

163 polymorphism (MSSCP) method of genetic profiling by choosing unique MSSCP profiles of 164 their PCR-amplified (Table S1, S2, Supplemental Information) V3 fragments of 16S rDNA, as 165 described in Tomczyk-Żak (Tomczyk-Żak et al., 2012). Briefly, in the applied colony, PCR166 technique colonies ofcultured biofilm strains were suspended in $100 \mu$ of lysis buffer, boiled for

$1675 \mathrm{~min}$ and centrifuged. Equal volumes of sterile cold water were added to the supernatants, and 168 these were used as templates in PCR for amplification of 160-bp long fragments of 16S rRNA 169 gene sequences.

170 In the case of difficult-to-lyse strains, the isolated genomic DNA of the cells (see above) was 171 used. 
174 To sequence the 16S rRNA genes of cultured bacteria selected by MSSCP, fragments of 175 16S rDNA were amplified using Paq Polymerase (Stratagene) and the universal primers 27F and 176 926R (Tables S1, Supplemental Information). Genomic bacterial DNAs (app. $3.7 \mathrm{ng} / \mu \mathrm{l}$ ) were the 177 templates in the optimized thermal cycle reactions (Table S2, Supplemental Information). PCR 178 products were purified with NucleoExtract II kit (Macherey-Nagel) and sequenced using the 179 same primers on an ABI3730/xl Genetic Analyzer (Applied Biosystem) at the Laboratory of 180 DNA Sequencing and Oligonucleotide Synthesis, IBB, PAS. Sequences were assembled using 181 Phred, Phrap and Consed Linux programs (Ewing et al., 1998; Ewing \& Green, 1998). The final 182 sequences were compared with available nucleotide databases GenBank (NCBI) using BLAST 183 (Altschul et al., 1997) (http://blast.ncbi.nlm.nih.gov/Blast.cgi). The sequences were deposited in 184 GenBank with the accession numbers GU213114-GU213156.

\section{Analysis of biodiversity}

186 The reads from pyrosequencing were processed using MOTHUR (Schloss et al., 2009) software according to Schloss Standard Operating Procedure described on MOTHUR's wiki (accessed 07.2014). Sequences were de-noised, filtered based on their quality and aligned using a Silvacompatible database of SSU rRNA genes provided by MOTHUR's authors. Potential chimeras were identified using UChimie (Edgar et al., 2011) algorithm and subsequently removed. Taxonomic assignments were completed with the RDP classifier (Wang et al., 2007). Operational Taxonomic Units (OTUs) were defined at the threshold of $98 \%$ of identity. Data from Tomczyk-Żak et al., (2013)(added under label: Clones) were analysed jointly using the same protocol. The mean length of sequences before processing in each group was: 1094 (clones), 131 (archaeal primers), 219 (generic primers) and 113 (actinobacterial primers), which was the basis for picking the higher threshold of OTU definition. 


\section{Functional analysis}

198 Functional capabilities of the biofilm have been assessed with the METAGENassist server 199 (Arndt et al., 2012), which maps phenotypes of known microbial species onto genera identified 200 during the taxonomic classification of reads. Final OTU sequences were used in this step.

\section{Scanning Electron Microscopy (SEM)}

202 Unprocessed samples of the biofilm were examined directly by environmental (ESEM - FEI 203 QUANTA 200) and field-emission (FESEM -JSM 7401F) scanning electron microscopy.

The elements $\mathrm{C}, \mathrm{O}, \mathrm{S}, \mathrm{As}$ and Fe were detected in unprocessed samples (dried only) of the biofilm by SEM (JEOL JSM-6380LA) coupled with an energy dispersive X-ray spectroscope (EDS). Analysis was performed for $17 \mathrm{~h}$ at an accelerating voltage of $20 \mathrm{kV}$ under low vacuum 207 (40 Pa).

The mineral composition of the bedrock was determined on a polished surface by SEM-EDS (JEOL JSM-6380LA) at a 10-mm working distance with $100 \mathrm{~s}$ of live time. The chemical composition of the interface was determined in thin layer embedded in resin by both, X-ray SEM-EDS (JEOL JSM-6380LA) and photoelectron spectroscopy (XPS) using Cameca SX100 operating with electron beam of $15 \mathrm{keV}$ at $10-40 \mathrm{nA}$. X-ray transition energy measurements

214 Microanalysis of Minerals and Synthetic Substances, Faculty of Geology, Warsaw University.

\section{Results}

\section{Structure of biofilm}


217 Exceptionally thick (up to $3 \mathrm{~cm}$ ) gelatinous biofilm covers several dozen square meters of the

218 rock wall in the Gertruda Adit. It was described in detail by Tomczyk-Żak et al, (2013), and here

219 we briefly recap its main features.
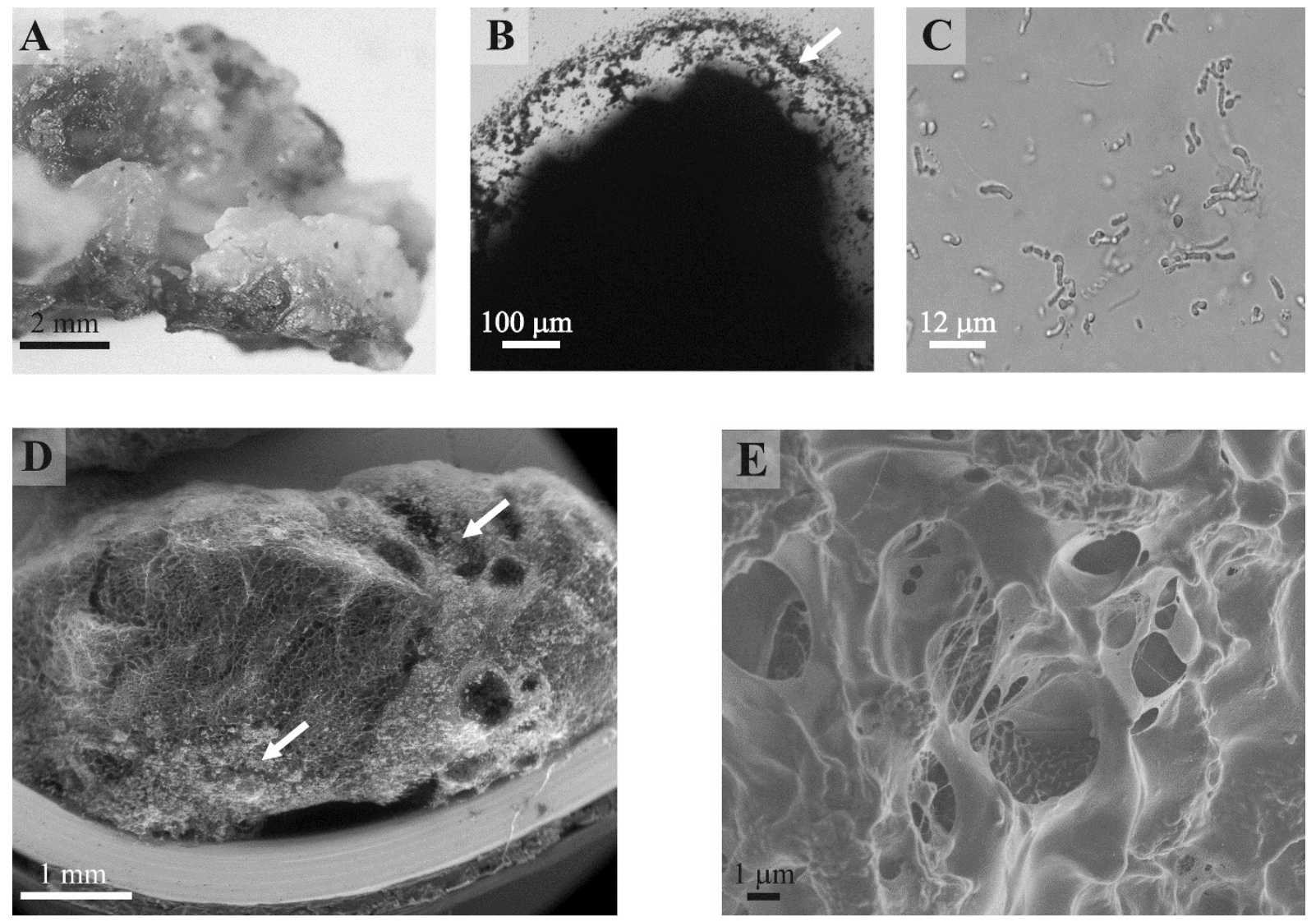

222 Fig. 1. Rock biofilm from Złoty Stok gold and arsenic mine.

223 A. Photograph of biofilm in situ; B. Micrograph of unstained biofilm in phase contrast; C.

224 Micrograph of cotton-blue stained biofilm presenting different bacteria, including

225 Actinobacteria; D,E. Scanning electron micrographs of an unprocessed rock biofilm sample (D:

226 ESEM magnification 50×; E: FESEM, magnification 5000×). Arrows indicate mineral particles. 
228 A single, separate group of biofilm occupies 5-10 $\mathrm{m}^{2}$. The overall morphological appearance of

229 the biofilm is variable in terms of colour, smoothness, consistency, moisture content, thickness

230 and tubercle dimensions, yet the internal structure revealed by SEM methodology shown in

231 every case the lattice structure of the matrix with vast empty or lower electron density spaces

232 (Fig. 1D,E). This heterogeneous, abundant, hydrated, inorganic matrix encloses both bacteria and

233 small mineral particles. Most of bacteria seem to occupy well-defined areas. Different

234 microscopy techniques uncovered a variety of bacterial shapes. Visualized bacteria represent

235 compact uniform communities as well as morphologically diverse clusters (Fig. 1C). Further

236 analyses were performed on three distinct layers of the sample - the biofilm (layer 0), an

237 interface between biofilm and underlying rock (layer 1), and finally the solid bed under the

238 biofilm (layer 2: see Fig. 2 schematic).

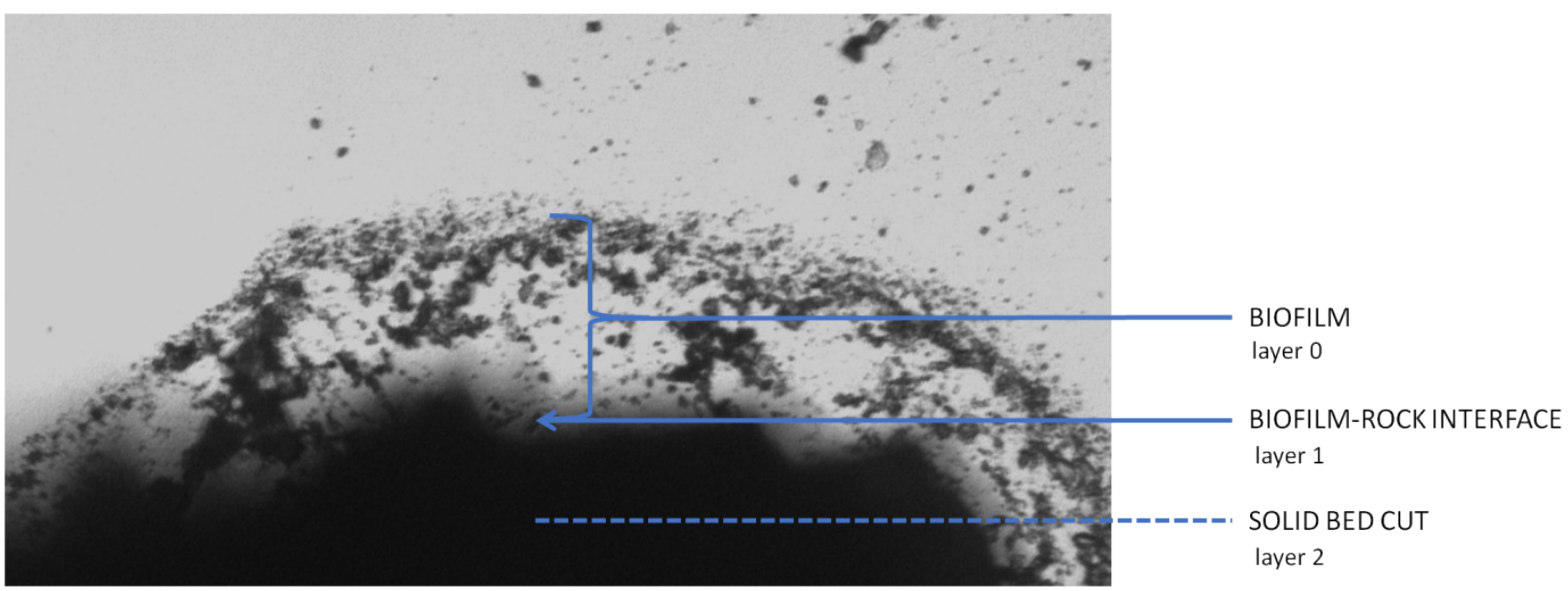

240 Fig. 2. Diagrammatic cross-section of the rock biofilm test sample. 
243 DNA extracted from the biofilm was processed as described in the Methods. Then, segments of

244 ribosomal 16S rRNA genes were amplified in three independent reactions using sets of primers

245 targeted at Archaea, Actinobacteria and an universal set (Table S1, Supplemental Information).

246 With a similar amount of sequenced DNA, we obtained an unequal number of reads from each

247 sample (see Table 1). The archaeal sample seemed to be sequenced most deeply as it had a high

248 number of reads and the lowest number of OTUs. This is reflected in the highest value of Good's

249 coverage estimator and the rarefaction curve approaching horizontal line (Fig. S1, curve B,

250 Supplemental Information). The other two samples appear to be under-sequenced, as the Good's

251 coverage value for them is only around 0.2 . In the case of the actinobacterial sample, this is

252 mainly the issue of the low number of good quality reads, since the value (100.6) of inverse

253 Simpson parameter (also called Simpson's Reciprocal Index, 1/D) suggests that we have

254 captured the majority of biodiversity in that sample. As for the universal primers the issue

255 appears to be related to the extremely high diversity revealed. The inverse Simpson parameters

256 are two orders of magnitude larger than in the other two cases, therefore it is very likely that

257 further sequencing would provide additional biodiversity.

Table 1. Basic statistics of three sequenced samples obtained using the MOTHUR software.

OTUs were defined at the threshold of 0.02 dissimilarity.

\begin{tabular}{l|l|c|c|c|c|c} 
Primer set & $\begin{array}{l}\text { No: } \\
\text { sequences/ } \\
\text { OTU }\end{array}$ & $\begin{array}{c}\text { Good's } \\
\text { coverage }\end{array}$ & Chao1 & $\begin{array}{c}\text { Inverse } \\
\text { Simpson }\end{array}$ & ACE & Shannon \\
\hline $\begin{array}{l}\text { Archaeal } \\
\text { unique } \\
\text { sequences }\end{array}$ & 14157 & 0.88 & 8088 & 164.8 & 13783 & 6.2
\end{tabular}




\begin{tabular}{l|c|c|c|c|c|c}
$\begin{array}{l}\text { Actinobacterial } \\
\text { unique } \\
\text { sequences }\end{array}$ & 327 & 0.21 & 3533 & 100.6 & 25955 & 5.3 \\
\hline $\begin{array}{l}\text { Universal } \\
\text { unique } \\
\text { sequences }\end{array}$ & 29427 & 0.20 & 333172 & 22150 & 1109221 & 10.0 \\
\hline $\begin{array}{l}\text { Archaeal } \\
\text { OTUs }\end{array}$ & 2574 & 0.91 & 5289 & 2.3 & 8917 & 2.8 \\
\hline $\begin{array}{l}\text { Actinobacterial } \\
\text { OTUs }\end{array}$ & 269 & 0.48 & 818 & 21 & 2403 & 4.6 \\
\hline $\begin{array}{l}\text { Universal OTUs } \\
\text { (20336 }\end{array}$ & 0.38 & 155644 & 3834 & 471427 & 9.4
\end{tabular}

261

262

263

Taxonomic assignments

264 There is some overlap between taxonomic coverage of the samples (Fig. 3), but overall primers

265 targeted at specific taxonomic groups had a relatively narrow and correct focus. Qualitative

266 overlap in the OUT assignment is shown in Supplementary Fig. S4. Archaeal OTUs could be

267 identified only by the primers targeted specifically at this taxonomic group. The majority of

268 assignments of actinobacterial primers were from that phylum. This is in agreement with studies

269 analysing the impact of PCR amplification on the proportion of rare biosphere in sequencing of

270 microbial communities (Gonzalez et al., 2012).

271 An overview of taxonomic assignments across all samples is shown in Fig.3. The tree represents

272 all the genera identified by their taxonomic assignments, but for clarity of mapping (the outer

273 layer of the bars) has been shown only for the genera that had at least 10 reads per primer set. 
274 Detailed breakdowns of taxonomic assignments of reads and OTUs are available in

275 Supplemental Information(Tables S3 and S4, respectively).

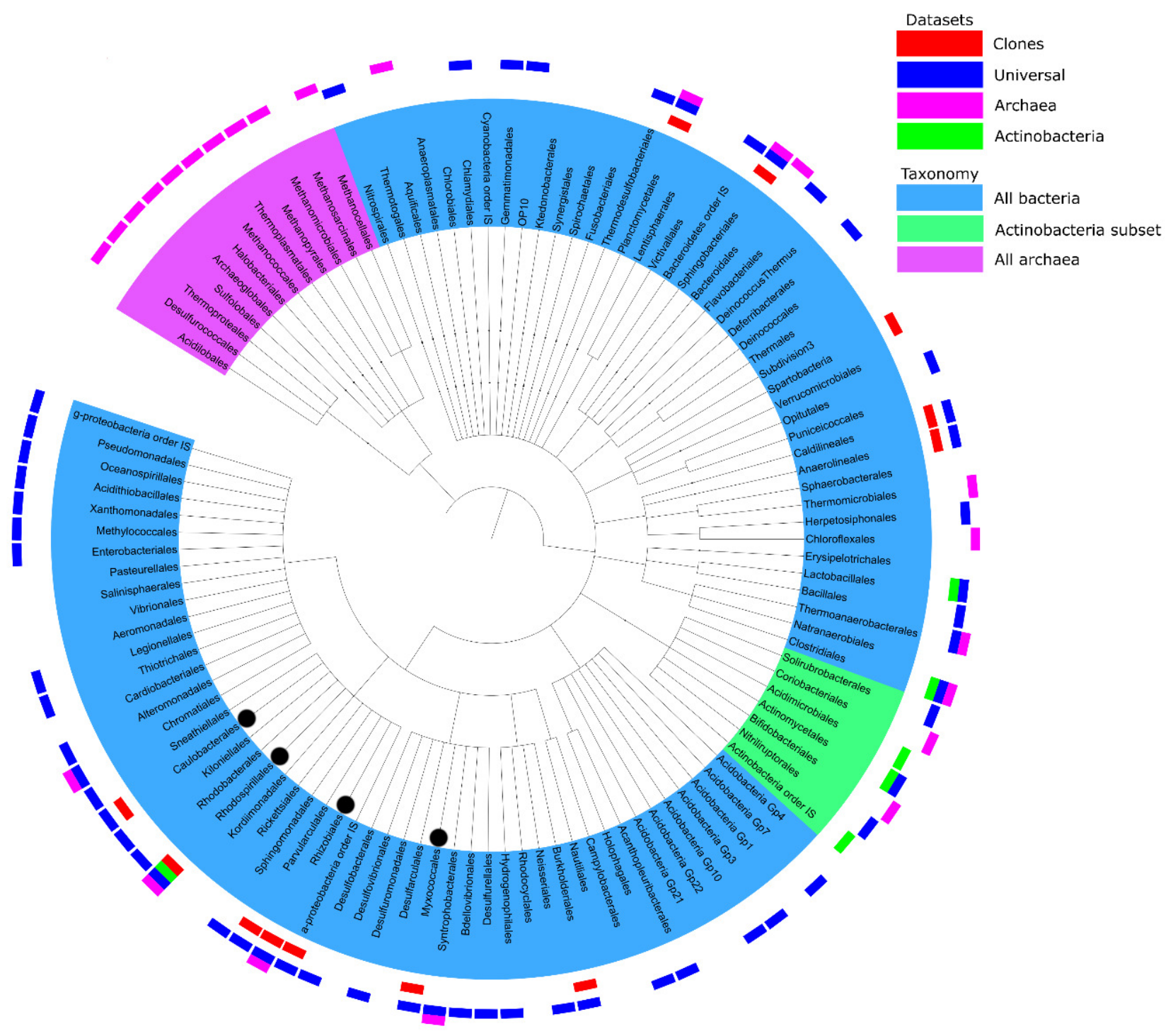

276

Fig. 3. Summary of taxonomic classification obtained from pyrosequencing of three samples based on classification of $16 \mathrm{~S}$ rRNA reads with the RDP classifier. Clades with more than 10 reads found in each primer set were marked with outer bars in blue, pink and green for universal, archaeal and actinobacterial primers respectively. Number of sequences in each data set is the same as number of unique sequences from Table 1. For a comparison, clones from 
282 Tomczyk-Żak et al, (2013) were added as the red bars. Branches of more than 1\% of total reads

283 were marked with black dot.

284

285 The analysed sequences were classified into twenty four phyla (partially depicted in Fig. 3):

286 Crenarchaeota (1.3\%), Euryarcheota (6.2\%), Acidobacteria (1.0\%), Actinobacteria (1.8\%),

287 Aquificae(0.1\%), Bacteroidetes (4.3\%), Chlamydiae (0.2\%), Chlorobi $(<0.1 \%)$, Chloroflexi

288 (2.3\%), Deferribacteres $\quad(<0.1 \%)$, Deinococcus-Thermus $\quad(<0.1 \%), \quad$ Firmicutes $\quad(1.6 \%)$,

289 Fusobacteria $(<0.1 \%)$, Gemmatimonadetes $(1.3 \%)$, Lentisphaerae $(<0.1 \%)$, Nitrospira $(0.1 \%)$,

290 Planctomycetes (0.5\%), Proteobacteria (78.3\%), Spirochaetes $(<0.1 \%)$, Synergistetes $(<0.1 \%)$,

291 Tenericutes $\quad(<0.1 \%), \quad$ Thermodesulfobacteria $\quad(0.2 \%), \quad$ Thermotogae $\quad(<0.1 \%)$ and

292 Verrucomicrobia (0.3\%). Many archeal sequences were assigned to several known methanogenic

293 phyla, such as Methanomicrobia, Methanococci or Methanopyri $(4.3 \%, 0.9 \%$ and $7.2 \%$ of all

294 sequences assigned to Archaea, respectively). Methanomicrobia were also found in the bottom

295 mat from this mine by Drewniak group of Laboratory of Environmental Pollution at University

296 of Warsaw (unpublished data, available at MGRAST id mgm4554870.3). The most highly

297 represented phyla in the Bacteria domain were Proteobacteria, Bacteroidetes, Actinobacteria,

298 Chloroflexi, Firmicutes and Acidobacteria (Table S3). The structure of the biofilm community

299 was dominated by bacteria belonging to $\alpha$-Proteobacteria (62.3\% of all reads), especially to

300 Rhizobiales (almost 8\% of all reads - 43911 - were assigned to that clade). Microorganisms

301 representing the Hyphomicrobiaceae, Beijerinckiaceae, Rhodospirillales and

302 Methylobacteriaceae were the most abundant groups of $\alpha$-Proteobacteria in the biofilm

303 population. The rest of the Proteobacteria sequences were assigned to $\delta$-Proteobacteria $(10.2 \%)$,

$304 \gamma$-Proteobacteria $(5.2 \%)$, and $\beta$-Proteobacteria $(0.6 \%)$ (listed in order of abundance). The 
305 Actinobacteria phylum was represented mainly by sequences from the Actinomycetales and 306 Solirubrobacterales orders, while Bacteroidetes was represented by the Sphingobacteriales order 307 and Flavobacteria class.

308 Assuming that the PCR with different primers introduced a heavy bias in the assessed structure 309 of the communities of all three samples (Xu et al., 2011), we did not attempt to statistically 310 assess relative abundances between Archaea, Actinobacteria and other taxonomic groups.

\section{Phenotypic analysis of taxonomic groups}

312 On the basis of taxonomic assignment, we performed an analysis of the phenotypic potential 313 using METAGENassist tool (see Methods). The results are summarized in Supplemental 314 Information (Fig. S2). This analysis suggests that almost all identified genera for which 315 phenotypic information was available represent aerobic species, while the majority of them are 316 autotrophic. There is a substantial number (over $60 \%$ in each group, according to 317 METAGENassist) of free-living species. The main group of biofilm microorganisms were

318 connected with the nitrogen cycle: ammonia oxidizers able to carry out the first step of 319 nitrification, and nitrite reducers, engaged in partial de-nitrification. Among them 320 Planctomycetes are, most probably, responsible for transformation of mineral nitrogen in this 321 environment. Diazotrophs assimilating atmospheric nitrogen were also frequently found. Other 322 identified microorganisms were sulphur metabolizing: sulphate reducers, sulphur oxidizers, and 323 metabolized other S-compounds. This finding was to be expected due to the large presence of 324 sulphur minerals such as pyrite $\left(\mathrm{FeS}_{2}\right)$, chalcopyrite $\left(\mathrm{CuFeS}_{2}\right)$, arsenopyrite $(\mathrm{FeAsS})$ and 325 dimethyl disulphide $\left(\mathrm{C}_{2} \mathrm{H}_{6} \mathrm{~S}_{2}\right)$. What was surprising was the lack of identified by 326 METAGENassist microorganisms capable of the reduction/oxidation of iron. Their presence was 
327 expected due to the high concentration of iron-containing minerals, the identification of such

328 microorganisms in clonal analysis and measured elevated activity of the biofilm siderophores

329 (Tomczyk-Żak et al., 2013). A detailed analysis of the list of identified taxa indicated that a vast

330 number of organisms can potentially be involved in iron redox transformations (e.g. bacterial

331 genera: Acidiphilium, Ferrithrix, Acidimicrobium, Anaeromyxobacter, Geothrix, Shewanella and

332 archeal genera: Ferroglobus, Geoglobus). It is notable, that among the cultivated strains

333 ,Paenibacillus and Stenotrophomonas represent genera able to reduce and oxidize iron,

334 respectively.

335 It is also noteworthy that, according to Metagenassist analysis, the biofilm microbiome

336 taxonomic profile suggests a wide range of metabolic capabilities, including, among others,

337 dehalogenation, degradation of aromatic hydrocarbons or chitin as well as metabolism of

338 pollutants and other toxic compounds. It is suspected that two groups of bacteria abundant in the

339 analysed sample, rhizobia and actinobacteria, already known for the presence of species capable

340 of dealing with complex compounds, are responsible for that result.

341 Some taxonomic branches might contain bacterial species capable of arsenic mobilization (e.g.

342 the genera Bosea, Microbacterium, Clostridium and Leptospirillum).

343 Cultured bacteria

344 A total of 52 different bacterial strains from Złoty Stok biofilm were isolated using different

345 media, and they were subsequently cultured. Their partial 16S rRNA genes were amplified and

346 sequenced. Taxonomic assignment was completed using the same approach as with reads from

347 pyrosequencing, i.e. MOTHUR implementation of RDP classifier. Results presented in Fig. 4

348 show 38 genera belonging to 4 phyla: Actinobacteria, Proteobacteria, Firmicutes and CFB (the 
349 last two groups are represented by few genera). Bacteria that could not be assigned to the genus

350 level (but classified to the family level) may represent species not yet identified. Interestingly,

351 strains of all four recognized taxonomic groups were isolated on all used media with the exception of the CFB group, representatives of which were not isolated on LB.

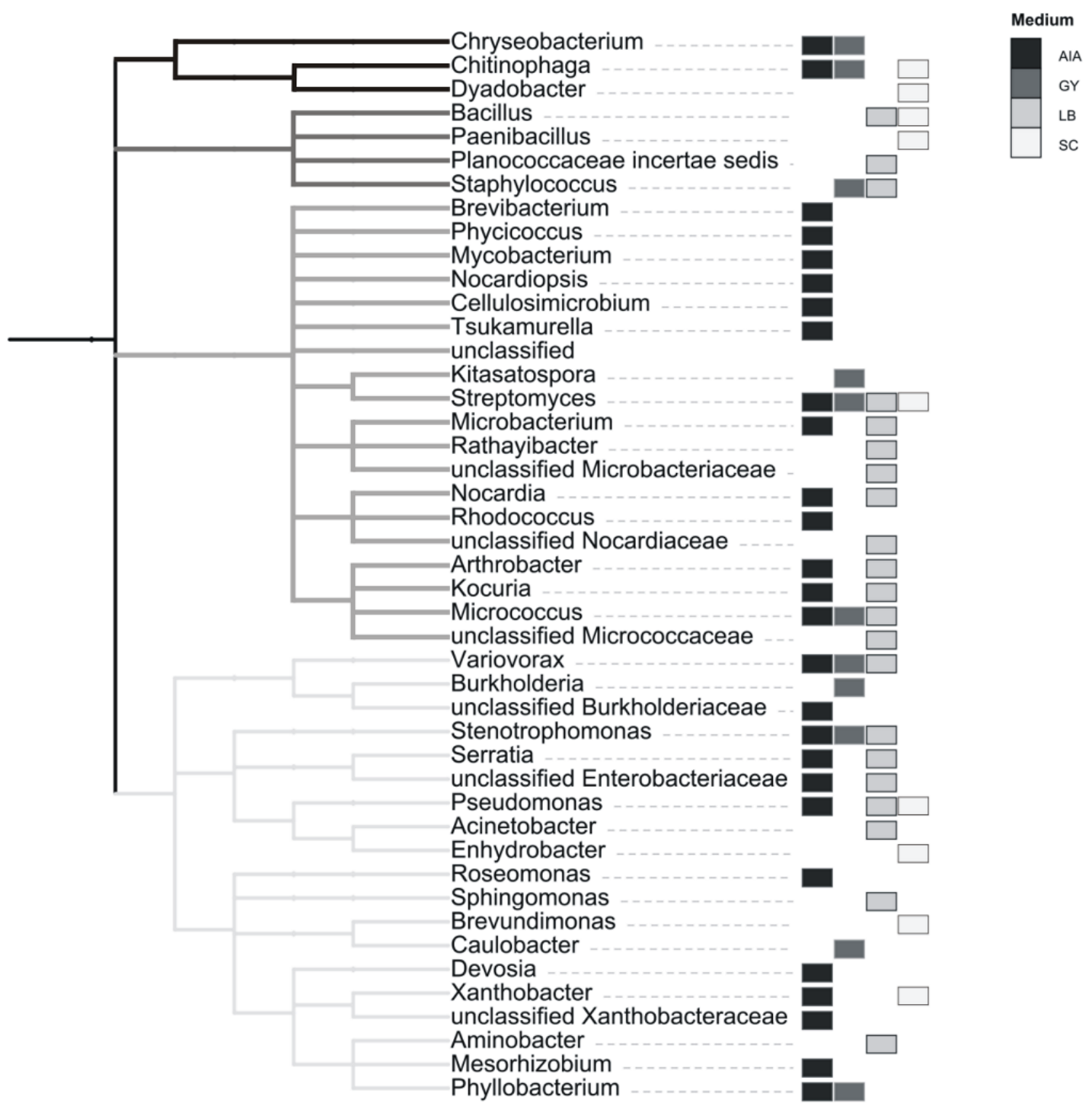

354 Fig. 4. Taxonomic classification of cultivated strains from rock biofilm based on

355 classification of $16 \mathrm{~S}$ rRNA genes with the RDP classifier. The topology reflects taxonomic 
356 classification of RDP database. Clades of phyla are highlighted in gray. Different cultivation

357 media are marked with gray rectangles.

358

359 Among 38 cultivable genera, 25 were also identified in a metagenomic approach. However, a 360 comparison of phenotypic potential between different groups (as assessed by Metagenassist, see 361 Fig. S2) indicates that the growth conditions used for bacteria isolation (see Methods) were not 362 overly selective. Ratios of genera with specific phenotypic traits (such as the ability to use 363 different energy sources, oxygen requirements, metabolic capability or biotic relationship) are 364 similar between the cultured bacteria and the samples derived using Actinobacteria-specific and 365 generic primers.

\section{Elemental analysis}

367 The analysis of solid bedrock under the biofilm was performed using SEM-EDS. Previous 368 geological studies of the Złoty Stok territory (Wierzchołowski, 1976; Przylibski, 2001; Muszer, 2011) indicated that we should expect minerals such as plagioclase, quartz, micas (biotite, muscovite), apatite, monazite, K-feldsparts and ore minerals (pyrite, pyrrothite, chalcopyrite,

371 sphalerite, loellingite, arsenopyrite). In the particular area analysed, we have found majority of

372 these minerals (Fig. S3, Supplemental Information), except for most of the ore minerals (only 373 pyrite was found) and arsenic minerals. 

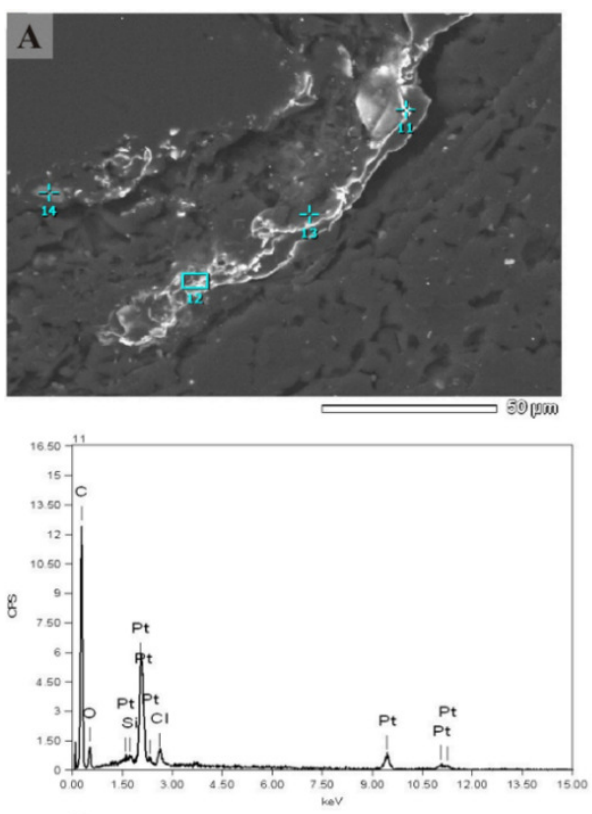

374

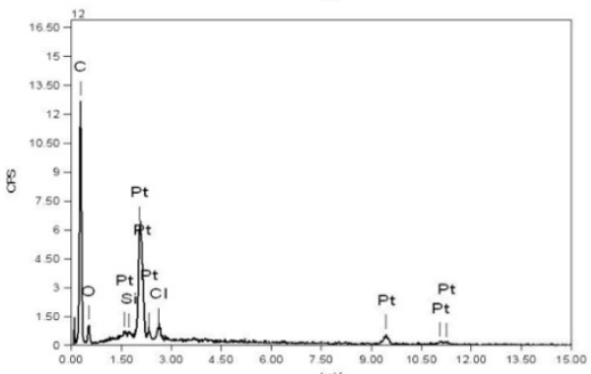

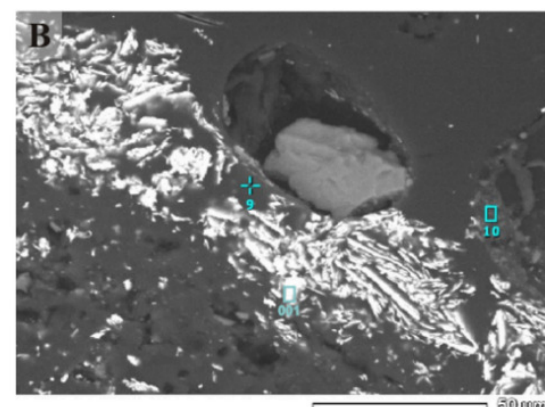
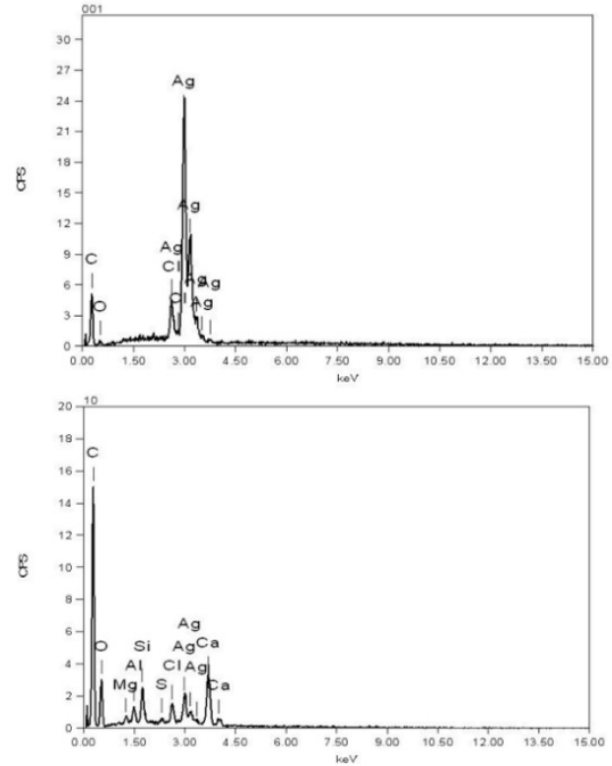

375

376

377

378

379

380

381

382

383

384

Fig. 5 SEM-EDS analysis of the interface between rock and biofilm.

Individual peak numbers from bottom spectrum panels correspond to spot numbers visible in the upper panels. Two columns represent two main metals: A - platinum, B - silver. Irregular diffused (non-crystal) metal intrusions are seen clearly on panel A.

The interface between rock and biofilm was analysed using both, SEM-EDS and X-ray techniques. The summary of quantitative analysis is present in Fig. S3 C (Supplemental Information). In essence, the qualitative picture revealed by this analysis did not differ much compared to solid bed. The presence of many secondary minerals (e.g. zircon, rutile, monazite, xenotime) and sulphide ore minerals (pyrrothite, chalcopyrite, sphalerite) was detected. However, we repeatedly observed interesting structures of the intrusions of pure noble metals 
385 (silver and platinum) in elemental form (Fig. 5). They did not look like typical crystal intrusions, 386 raising a question of their biogenic origin. Arsenic intrusions were not observed.

387

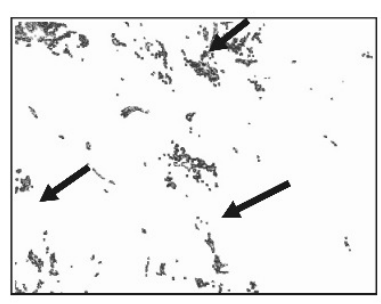

Carbon

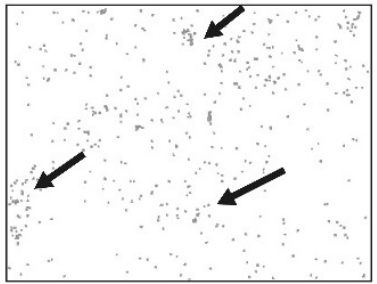

Arsenic

$250 \mu \mathrm{m}$

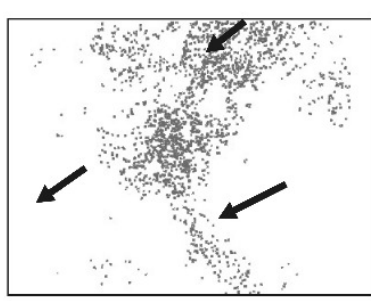

Sulphur

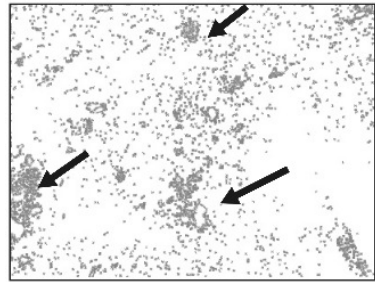

Iron

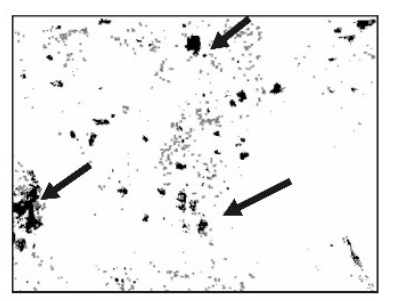

Oxygen / Silicon

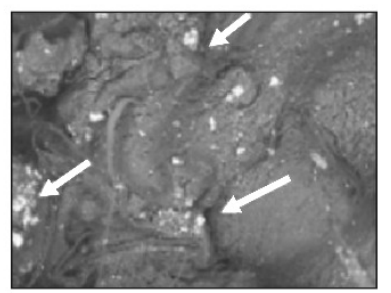

Biofilm sample

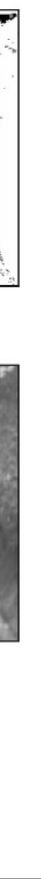

Fig. 6. Mapping of elements in the rock biofilm sample. SEM-EDS elemental maps showing $\mathrm{C}, \mathrm{S}, \mathrm{O}$, As and Fe distribution in the biofilm sample.

In the oxygen/silicon panel oxygen is presented by gray colour and silicon by black colour. Arrows indicate large mineral intrusions.

Elemental analysis of the biofilm layer was performed using the SEM-EDS mapping technique (see Methods). Distribution of several elements, such as carbon, sulphur, oxygen (together with silicon), arsenic and iron, were analysed on the biofilm surface (Fig. 6). Some elements, such as carbon, sulphur and oxygen/silicon were distributed unevenly, and their location was highly correlated. Arsenic and iron were distributed more evenly, with a tendency to concentrate in 
398 mineral particles. Notably, arsenic was nearly absent in areas of high carbon concentration, while

399 the concentration of iron increased in the areas where carbon and sulphur were present. As stated

400 above, the biofilm contains numerous mineral intrusions of different sizes in its volume (shown

401 in Fig. 1).

402

403 Discussion

404 In this study we analysed the exceptionally abundant biofilm developing in extremely 405 oligotrophic environment on the walls of the Gertruda Adit of the Złoty Stok mine. Both 406 elemental analysis and biodiversity assessment revealed unexpected diversity and complexity. 407 Presented work sheds new light on several areas.

\section{Rich ecosystem of oligotrophs}

409 The microbiota of this ancient gold mine probably represents indigenous microorganisms from 410 the ore and fracture water, plus others that were brought in with spruce wood beams and other 411 timbers, and also by the mine workers of fifty years ago and earlier. However, the present 412 environmental conditions (especially the high arsenic concentration) are more favourable for 413 indigenous microorganisms. These conditions have led to a level of bacterial diversity that is 414 comparable with that of partially reclaimed tailings or old, inhabited caves (Shannon index 8-12) 415 rather than drilled rock cores or newly formed or opened caves (Shannon index 1-5).

416 We have assessed biodiversity using pyrosequencing of fragments of the 16S rRNA gene, which 417 were amplified using primers targeted at Archaea and Actinobacteria, and using universal 418 primers. As a result, a large number of additional taxonomic groups has been revealed, 
419 substantially enriching (50 taxonomic families more, that is almost $30 \%$ ) the assessment 420 obtained using universal primers only. This alone is not surprising, as the bias coming from the

421 choice of primers has been a topic of intensive studies over the last few years (Bergmann, 2011, 422 Cai L, 2013). The high biodiversity (Shannon index reaching 10) was reflected in experiments 423 with cultured bacteria: major taxonomic groups revealed by pyrosequencing were later identified 424 within cultured bacteria. In total we have found almost 4000 OTUs. The majority of organisms 425 are from Proteobacteria, Actinobacteria and the archaeal genera of methanogenic capabilities. 426 However, there is very likely a long tail of strains capable of perusing complex biofilm structure 427 for growth, which could be revealed by deeper sequencing.

428 Independently, we cultured 52 microbial species and sequenced their near full-length 16S rRNA genes. As expected, there was an overlap in the biodiversity assessment between the culture430 dependent and culture-independent analyses. Speculating based on the taxonomic assignments, it 431 seems that more than half of the revealed community organisms possess small genomes, 1-2 Mb in size, suggesting their specialized rather than versatile metabolism (Giovannoni et al., 2005).

433 Hence, the mutual interactions between biofilm organisms seem to be very complex. We could 434 not reliably identify known examples of syntrophic interactions between pairs of bacterial 435 species. However, functional analysis (which infers from cultivable, well-studied species) 436 showed many potential energy sources, further supporting the hypothesis that many 437 complementary functional interactions occur between species inhabiting the biofilm. Based on 438 metagenomic analysis, we can distinguish three types of functional interactions (involving 439 nitrogen, iron together with sulphur, and finally methane) between biofilm microorganisms and 440 the environment as shown schematically in Fig. 7. Some reactions were confirmed by analysis in 441 the previous work (Tomczyk-Żak et al., 2013). The major sources of energy appear to be some 
442 nitrogen compounds, which is reflected in increased levels of nitrogen and nitrous oxide. These

443 are likely supplemented by sulphur compounds, given that sulphur is an abundant element in

444 minerals present in the habitat. Another interesting capability is methano/methylotrophism, as it

445 complements the methanogenic activity of bacteria present in bottom sediments of this mine

446 (Drewniak et al., 2012). Obviously, the majority of microorganisms will be capable of perusing

447 iron ions, as the energy sources, given the high concentration of iron-containing minerals, but

448 this process is missing in the results of METAGENassist analysis, most likely due to limitations

449 of available phenotypic databases (e.g. BacMap

450 https://www.ncbi.nlm.nih.gov/pubmed/22135301, the data source for METAGENassist, contains

451 less than 2000 genomes). Numerous members of genera showing iron-capturing capabilities have

452 been detected in clonal analysis (Tomczyk-Żak et al., 2013). As mentioned above, among

453 cultivated strains, two were able to utilize Fe ions.
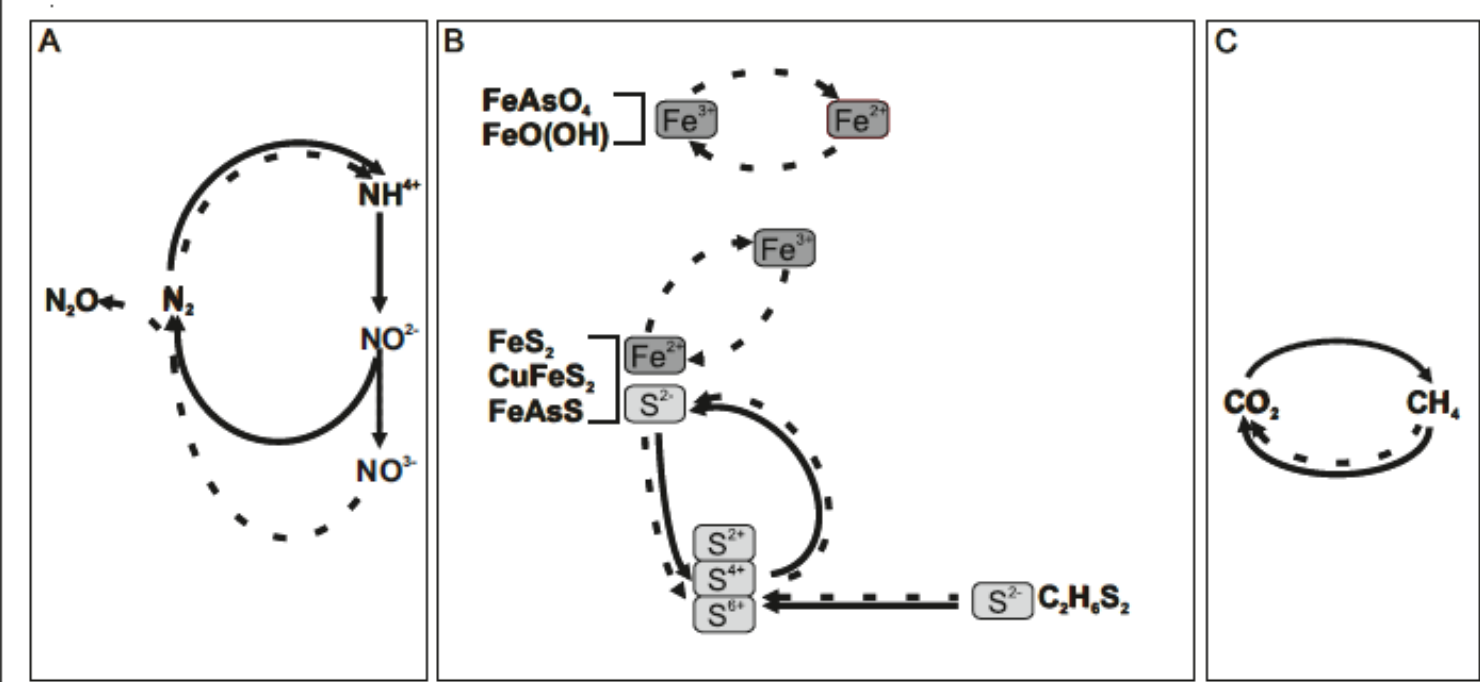

Legend:

- - data from Tomczyk-Żak et al. 2013

data from MetagenAssist 
455 Fig. 7. Model showing putative participation of rock biofilm microorganisms in the 456 transformation of chemical compounds in the Zloty Stok mine.

457 METAGENassist predictions from this study overlap with data from our previous report. 458 Undetected transformations are implied by literature data. Chemical transformation: A. nitrogen; 459 B. iron and sulphur; C. methane.

The presence of bacterial species in the Złoty Stok mine that are highly resistant to arsenic has

462 been known for a few years (Drewniak et al., 2008). The key genes involved in such a process, 463 i.e. arsenite oxidase or arsenate reductase, were detected in other studies by PCR amplification 464 (Tomczyk-Żak et al., 2013). However we were unable to culture a bacterial species that uses 465 arsenic as an energy source. Also, so far, there has been no clear answer as to which species from 466 the rock biofilm is capable of arsenic mobilization, although Drewniak and co-workers identified 467 and cultured such a species in the bottom mat of the mine (Drewniak et al.,2010; 2012; 2014).

468 Given that arsenic has an even distribution in the biofilm, it is plausible that most of the biofilm 469 inhabitants do not use arsenic compounds as energy sources. Some studies, based on PCR 470 amplification of arsenite oxidase or arsenate reductase genes, suggest that these enzymatic 471 features are much more common than previously thought (Oremland \& Stolz, 2003). However, 472 given the toxicity of arsenic, it is more plausible that most of organisms would prefer to use other 473 sources of energy over inorganic arsenic.

\section{Mobilization of other elements}

475 Precious metals such as gold, silver and platinum typically exist in the rocks as part of iron ore.

476 In the Złoty Stok mountain area, polymetallic mineralisations have been noted (Przylibski, 
477 2001). Metal inclusions, if present, have the characteristic shapes of grains of several types.

478 Precious metals are present in the interface between the solid bed and the biofilm; however, the

479 shape of intrusions is strikingly unusual for all elements analysed. It is tempting to suggest that 480 these grains are of biogenic origin. Bacteria, perusing iron compounds from an ore, also capture 481 the precious metals. As these elements are not utilized in any way, they might be deposited in an 482 amorphous form. Also, the co-occurrence of methanotrophs and methanogenes can substantially 483 influence the metal and metalloids mobilization. Choi et al, (2006) showed that methanotrophy 484 may play a role in either the solubilization or immobilization of many metals in situ.Several 485 organisms, e.g. Streptomyces, Desulfovibrio and Variovorax from among the genera described as 486 able to recover precious metals, have been detected in the studied biofilm. Bacterially induced 487 mineralization processes become well recognized and led to the use of microorganisms for 488 recovery of precious metals, especially gold, silver and platinum (Das, 2010).

\section{Conclusions}

Limited resources in the environment should limit biodiversity according to Gause's law.

491 Competing for scarce sources of energy leads typically to extinction of the weaker species.

However, certain habitats support high biodiversity despite limited resources, and this situation is called "the paradox of the plankton" (Hutchinson, 1961), as plankton was the first example of this kind of environment. The rock biofilm present in the Złoty Stok mine is another example of such a paradox. While the environment is extremely oligotrophic and has no light sources, the observed community exhibits extremely high richness and complexity. This cannot be explained by large spatiotemporal dynamics of the population, as the bacteria in the biofilm are mostly immobilized. However, given the spatial difference in concentration of arsenic and other metals 
499 across the analysed layers, it is plausible that there is a gradient of inorganic compounds 500 including trace elements within the biofilm structure, which support the heterogeneity of the 501 community. Additional support might come from the water; organic carbon from the water 502 residing on the biofilm is below $160 \mathrm{mg} / \mathrm{L}$. Chemical analysis indicated that the water samples 503 from the Gertruda Adit are likely to be of atmospheric origin. While there is no visible dripping 504 water, the moisture of the walls most likely has an external origin. Therefore, the outermost 505 layers of the biofilm have access to additional organic compounds at low concentrations.

506 In conclusion, we extended our previous investigations of microbial biofilm composition using 507 both culture dependent and culture independent methods. Furthermore, we correlated microbial 508 community structure to mineral and elemental composition of both, biofilm and rock, and based 509 on the analysis of taxonomic assignments, we predicted biogeochemical transformation 510 pathways. The prediction agrees with literature data, but in the absence of direct experimental 511 evidence remains a rough speculation.

512 The special features of this community are its abundance and very high diversity. As expected, 513 amplicons pyrosequencing with specific primers uncovered the presence of archaeal species and 514 abundant actinobacterial population which had escaped from previous clonal analysis.

515 In this report, the ecological "paradox of plankton" is postulated as the explanation of both the 516 extremely high microbial diversity and the abundance of the mine rock biofilm developing in an 517 oligotrophic environment. The cycling energy flow of most prominent minerals in the absence of 518 evident influx of organic matter could explain the relationship between geochemical processes 519 and the activity of microorganisms in this peculiar anthropogenic environment. 


\section{Acknowledgements}

523 We gratefully acknowledge prof. K. Błaszczyk for his critical reading of the manuscript.

\section{Conflict of interest}

526

527

528

529

530

531

532

533

534

535

536

537

538

539

540

541

542

543

544

545

546

547

548

549

\section{References:}

Altschul SF, Madden TL, Schäffer AA, Zhang J, Zhang Z, Miller W \& Lipman DJ. 1997. Gapped BLAST and PSI-BLAST: a new generation of protein database search programs. Nucleic Acids Res. 25: 3389-3402.

Arndt D, Xia J, Liu Y, Zhou Y, Guo AC, Cruz J. A,... Wishart DS. 2012. METAGENassist: a comprehensive web server for comparative metagenomics. Nucleic Acids Research, 40(Web Server issue), W88-W95. http://doi.org/10.1093/nar/gks497

Baker BJ \& Banfield JF. 2003. Microbial communities in acid mine drainage. FEMS Microbiol. Ecol. 44: 139-152.

Bergmann, G. T., Bates, S. T., Eilers, K. G., Lauber, C. L., Caporaso, J. G., Walters, W. A., ... Fierer, N. 2011. The under-recognized dominance of Verrucomicrobia in soil bacterial communities. Soil Biology \& Biochemistry, 43(7), 1450-1455. http://doi.org/10.1016/j.soilbio.2011.03.012

Cai L, Ye L, Tong AHY, Lok S, Zhang T. 2013. Biased diversity metrics revealed by bacterial $16 \mathrm{~S}$ pyrotags derived from different primer sets. PLoSONE 8(1): e53649. doi:10.1371/journal.pone.0053649

Choi DW, Do YS, Zea CJ, McEllistrem MT, Lee SW,...DiSpirito AA. 2006. Spectral and thermodynamic properties of $\mathrm{Ag}(\mathrm{I}), \mathrm{Au}(\mathrm{III}), \mathrm{Cd}(\mathrm{II}), \mathrm{Co}(\mathrm{II}), \mathrm{Fe}(\mathrm{III}), \mathrm{Hg}(\mathrm{II}), \mathrm{Mn}(\mathrm{II}), \mathrm{Ni}(\mathrm{II})$, $\mathrm{Pb}(\mathrm{II}), \mathrm{U}(\mathrm{IV})$, and $\mathrm{Zn}(\mathrm{II})$ binding by methanobactin from Methylosinus trichosporium OB3b. J. Inorg.Biochem.100:2150 - 2161. doi.org/10.1016/i.jinorgbio.2006.08.017

Das N. 2010. Recovery of precious metals through biosorption - A review. Hydrometallurgy 103: 180-189. 
550

551

552

553

554

555

556

557

558

559

560

561

562

563

564

565

566

567

568

569

570

571

572

573

574

575

576

577

578

579

580

581

582

583

584

585

Drewniak L, Maryan N, Lewandowski W, Kaczanowski S \& Sklodowska A. 2012. The contribution of microbial mats to the arsenic geochemistry of an ancient gold mine. Environ. Pollut. 162: 190-201.

Drewniak L, Matlakowska R, Rewerski B \& Sklodowska A. 2010. Arsenic release from gold mine rocks mediated by the activity of indigenous bacteria. Hydrometallurgy 104: 437442.

Drewniak L, Rajpert L, Mantur A \& Sklodowska A. 2014. Dissolution of arsenic minerals mediated by dissimilatory arsenate reducing bacteria: estimation of the physiological potential for arsenic mobilization.BioMed Research International. DOI: 10.1155/2014/841892

Drewniak L, Styczek A, Majder-Lopatka M \& Sklodowska A. 2008. Bacteria, hypertolerant to arsenic in the rocks of an ancient gold mine, and their potential role in dissemination of arsenic pollution. Environ. Pollut. 156: 1069-1074.

Edgar RC, Haas BJ, Clemente JC, Quince C \& Knight R. 2011. UCHIME improves sensitivity and speed of chimera detection. Bioinforma. Oxf. Engl. 27: 2194-2200.

Ewing B \& Green P. 1998. Base-calling of automated sequencer traces using phred. II. Error probabilities. Genome Res. 8: 186194.

Ewing B, Hillier L, Wendl MC \& Green P. 1998. Base-calling of automated sequencer traces using phred. I. Accuracy assessment. Genome Res. 8: 175-185.

Hutchinson GE. 1961. The paradox of the plankton. Am Nat.;95(882):137-145.

Gadd GM. 2010. Metals, minerals and microbes: geomicrobiology and bioremediation. Microbiology 156: 609-643.

Giovannoni SJ, TrippHJ, Givan S, Podar M,Vergin KL,...Mathur EJ. 2005. Genome streamlining in a cosmopolitan oceanic bacterium. Science 309: 1242-1245. DOI:10.1126/science.1114057

Gonzalez JM, Portillo MC, Belda-Ferre P \& Mira A. 2012. Amplification by PCR artificially reduces the proportion of the rare biosphere in microbial communities. PLOS ONE 7: e29973.

Gorbushina AA. 2007. Life on the rocks. Environ. Microbiol. 9: 1613-1631.

Gorbushina AA, Lyalikova NN, Vlasov DY \& Khizhnyak TV. 2002. Microbial communities on the monuments of Moscow and St. Petersburg: biodiversity and trophic relations. Microbiology 71: 350-356.

Johnson DB \& Hallberg KB. 2003. The microbiology of acidic mine waters. Res. Microbiol. 154: 466-473.

Labrenz M \& Banfield JF. 2004. Sulfate-reducing bacteria-dominated biofilms that precipitate $\mathrm{ZnS}$ in a subsurface circumneutral-pH mine drainage system. Microb. Ecol. 47: 205-217. 
586 Lin L-H,Pei-Ling W, Rumble D, Lippmann-Pipke J, Boice E,...Onstott TC. 2006. Long-

587 termsustainability of a high-energy, low-diversity crustal biome. Science 314: 479-482

588 DOI: $10.1126 /$ science. 1127376

589 Macalady JL, Jones DS \& Lyon EH. 2007. Extremely acidic, pendulous cave wall biofilms from 590 the Frasassi cave system, Italy. Environ. Microbiol. 9: 1402-1414.

591

592

593

594

595

596

597

598

599

600

601

602

603

604

605

606

607

608

609

610

611

612

613

614

615

616

617

618

619

620

621

Muszer A. 2011. Gold at Złoty Stok - history, exploitation, characteristic and perspectives Gold in Poland. AM Monogr. 2: 45-61.

Oremland RS \& Stolz JF. 2003. The ecology of arsenic. Science 300: 939-944.

Pasić L, Kovce B, Sket B \& Herzog-Velikonja B. 2010. Diversity of microbial communities colonizing the walls of a Karstic cave in Slovenia. FEMS Microbiol. Ecol. 71: 50-60.

Portillo MC, Gonzalez JM \& Saiz-Jimenez C. 2008. Metabolically active microbial communities of yellow and grey colonizations on the walls of Altamira Cave, Spain. J. Appl. Microbiol. 104: 681-691.

Portillo MC, Saiz-Jimenez C \& Gonzalez JM. 2009. Molecular characterization of total and metabolically active bacterial communities of "white colonizations" in the Altamira Cave, Spain. Res. Microbiol. 160: 41-47.

Przylibski TA. 2001. Radon and its daughter products behaviour in the air of an underground tourist route in the former arsenic and gold mine in Złoty Stok (Sudety Mountains, SW Poland). J. Environ. Radioact. 57: 87-103.

Santelli CM, Edgcomb VP, Bach W \& Edwards KJ. 2009. The diversity and abundance of bacteria inhabiting seafloor lavas positively correlate with rock alteration. Environ. Microbiol. 11: 86-98.

Schabereiter-Gurtner C, Saiz-Jimenez C, Piñar G, Lubitz W \& Rölleke S.2002a. Altamira cave Paleolithic paintings harbor partly unknown bacterial communities. FEMS Microbiol. Lett. 211: 7-11.

Schabereiter-Gurtner C, Saiz-Jimenez C, Piñar G, Lubitz W \& Rölleke S. 2002b. Phylogenetic $16 \mathrm{~S}$ rRNA analysis reveals the presence of complex and partly unknown bacterial communities in Tito Bustillo cave, Spain, and on its Palaeolithic paintings. Environ. Microbiol. 4: 392-400.

Schabereiter-Gurtner C, Saiz-Jimenez C, Piñar G, Lubitz W \& Rölleke S. 2004. Phylogenetic diversity of bacteria associated with Paleolithic paintings and surrounding rock walls in two Spanish caves (Llonin and La Garma). FEMS Microbiol. Ecol. 47: 235-247.

Schloss PD Westcott SL, Ryabin T, Hall JR, Hartmann M, Hollister EB...Weber CF. 2009. Introducing mothur: open-source, platform-independent, community-supported software for describing and comparing microbial communities. Appl. Environ. Microbiol. 75: 75377541. 
622 Tomczyk-Żak K, Kaczanowski S, Drewniak Ł, Dmoch Ł, Sklodowska A \& Zielenkiewicz U.

623

624

625

626

627

628

629

630

631

632

633

634

635

636

637

638 2013. Bacteria diversity and arsenic mobilization in rock biofilm from an ancient gold and arsenic mine. Sci. Total Environ. 461: 330-340.

Tomczyk-Żak K, Kaczanowski S, Górecka M \& Zielenkiewicz U. 2012. Novel application of the MSSCP method in biodiversity studies. J. Basic Microbiol. 52: 104-109.

Wang Q, Garrity GM, Tiedje JM \& Cole JR. 2007. Naive Bayesian classifier for rapid assignment of rRNA sequences into the new bacterial taxonomy. Appl. Environ. Microbiol. 73: 5261-5267.

Wierzchołowski B. 1976. Granitoids of the Kłodzko-Złoty Stok massif and their contact influence on the country rocks (petrographic characteristics). Geol. Sudet. 11: 7-147.

Xu L, Ravnskov S, Larsen J \& Nicolaisen M. 2011. Influence of DNA extraction and PCR amplification on studies of soil fungal communities based on amplicon sequencing. Can. J. Microbiol. 57: 1062-1066.

Zimmermann J, Gonzalez JM \& Saiz-Jimenez C. 2006. Epilithic biofilms in Saint Callixtus Catacombs (Rome) harbour a broad spectrum of Acidobacteria. Antonie Van Leeuwenhoek 89: 203-208. 